\title{
If airlines can do it, we can too...
}

\author{
Camille L. Hancock-Friesen, MD, ${ }^{\mathrm{a}, \mathrm{b}}$ and R. D. B. Jaquiss, MD ${ }^{\mathrm{a}, \mathrm{c}}$
}

From the ${ }^{a}$ UT Southwestern Medical Center, Dallas, Tex; ${ }^{b}$ Dell Children's Medical Center, Austin, Tex; and

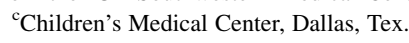

Disclosures: Authors have nothing to disclose with regard to commercial support.

Received for publication Oct 30, 2017; accepted for publication Nov 8, 2017; available ahead of print Dec 6, 2017. Address for reprints: R. D. B. Jaquiss, MD, 1935 Medical District Dr, Dallas, TX 75235 (E-mail: Robert.jaquiss@ utsouthwestern.edu).

J Thorac Cardiovasc Surg 2018;155:688-9

$0022-5223 / \$ 36.00$

Copyright (c) 2017 by The American Association for Thoracic Surgery

https://doi.org/10.1016/j.jtcvs.2017.11.022

The article by Hickey and colleagues ${ }^{1}$ in this issue of the Journal, entitled "Chasing the 6-sigma: Drawing Lessons from Cockpit Culture," is an essay advocating the application of the safety culture of the airline industry to the care of children undergoing congenital heart surgery, although its message has application across all of cardiothoracic surgery and beyond. The team at Toronto Hospital for Sick Children has thus moved the complication conversation upstream to the events that precede adverse outcomes by using the threat and error model developed in aviation. This group has previously contributed to enhancing the safety culture in pediatric cardiac surgery by the use of a visual display depicting each patient journey during weekly "performance rounds." Their current work adds the concept of "line operating safety audits" and the recommendation that the tools for establishing a robust safety culture be incorporated into surgical training (as described by teams at Aberdeen and Oxford in the United Kingdom and now at Brigham and Women's Hospital in the United States). ${ }^{2,3}$

In their analysis of the impact of performance rounds, Hickey and colleagues ${ }^{1}$ have found that the semiquantitative and qualitative data presented during performance rounds provide qualitative benefits, even if demonstrated effects on quantitative outcomes are more elusive. Such qualitative benefits are detailed briefly in their article and include improvements in communication and team function. A quantitative outcome that is not presented, but would be interesting to parse, is any influence on the failure to rescue rate described by Pasquali and associates. ${ }^{4}$ Although failure to rescue is downstream of the complication, there might be a positive effect consequent to enhanced communication and collaboration. Hickey and colleagues ${ }^{1}$ also did not discuss the use of "big data" to identify threat signals in physiologic monitoring. 5

Apart from quantitative outcomes, there are semiquantitative modalities useful in evaluating team performance. De Leval and colleagues ${ }^{6}$ have studied the high-performance teams in Formula 1 pit stops and derived an assessment of the essential domains of teamwork, including categories of "leadership and teamwork," "task management,"

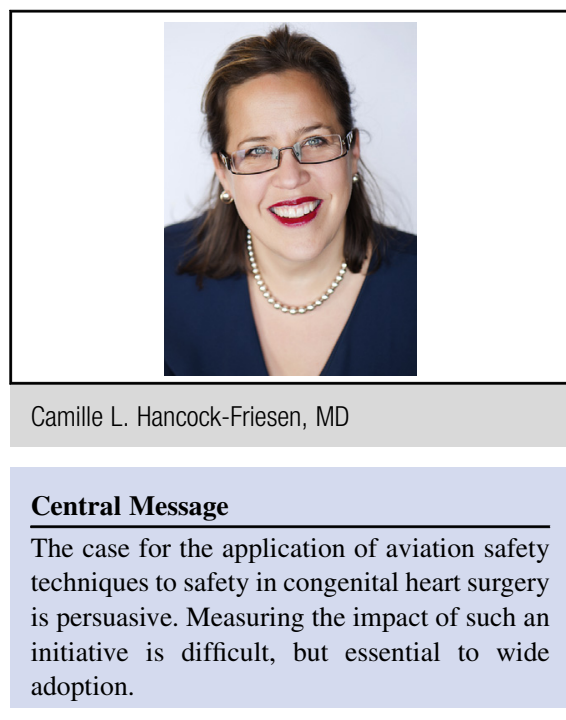

See Article page 690.

"workspace and equipment," and "situation awareness," and applied these metrics in the clinical realm. Although they are often viewed as the country cousins to quantitative outcomes, there are growing rigor and acceptance of qualitative methodologies in the analysis of complex adaptive systems, which could be harnessed to characterize positive effects arising from performance rounds. ${ }^{7}$ These methodologies include qualitative description and ethnography, ${ }^{8}$ observation (like line operating safety audits), focus groups, interviews, scales, and case studies (like performance rounds). The use of qualitative tools would strengthen the anecdotal description of the positive outcomes in the article of Hickey and colleagues, ${ }^{1}$ when in fact these are central and critical outcomes that certainly require the commitment of additional resources and time. The need to demonstrate objectively the merit of the changes that Hickey and colleagues ${ }^{1}$ advocate is especially relevant in the present era of financial belt-tightening, staff cutbacks, and seemingly ever-diminishing resources. However evident the merits of an enhanced safety culture may appear to us clinicians, value is now another yardstick by which any novel program will also be measured. An initiative must not only be effective, it must be cost-effective.

\section{References}

1. Hickey EJ, Halvorsen F, Laussen PC, Hirst G, Schwartz S, Van Arsdell GS Chasing the 6-sigma: drawing lessons from the cockpit culture. J Thorac Cardiovasc Surg. 2018;155:690-6.e1.

2. Catchpole KR, Dale TJ, Hirst DG, Smith JP, Giddings TA. A multicenter trial of aviation-style training for surgical teams. J Patient Saf. 2010;6:180-6. 
3. Yule S, Flin R, Paterson-Brown S, Maran N, Rowley D. Development of a rating system for surgeons' non-technical skills. Med Educ. 2006;40:1098-104.

4. Pasquali S, He X, Jacobs JJ, Jacobs ML, O’Brien SM, Gaynor JW. Evaluation of failure to rescue as a quality metric in pediatric heart surgery: an analysis of the STS Congenital Heart Surgery Database. Ann Thorac Surg. 2012;94:573-9; discussion 579-80.

5. Lin YL, Guerguerian AM, Tomasi J, Laussen P, Trbovich P. Usability of data integration and visualization software for multidisciplinary pediatric intensive care: a human factors approach to assessing technology. BMC Med Inform Decis Mak. 2017;17:122.
6. Catchpole KR, de Leval MR, McEwan A, Pigott N, Elliott MJ, McQuillan A et al. Patient handover from surgery to intensive care: using Formula 1 pitstop and aviation models to improve safety and quality. Ped Anesth. 2007; 17:470-8.

7. Barasa EW, Molyneux S, English M, Cleary S. Hospitals as complex adaptive systems: a case study of factors influencing priority setting practices at the hospital level in Kenya. Soc Sci Med. 2007;174:104-12.

8. Atkinson P, Pugsley L. Making sense of ethnography and medical education. Med Educ. 2005;39:228-34. 